\title{
A Review of Mobile Learning Research at Home and Abroad in Recent 20 Years*
}

\author{
Jiaosheng Qiu \\ Taishan University, China
}

\begin{abstract}
Mobile learning is a new learning mode with the increasing popularity of multimedia technology and Internet application. It not only emphasizes the learner's subjective status and initiative, but also helps learners construct meanings through various forms of interaction. It is becoming a research area of multi-disciplinary participation, cross-cutting and Multi-thematic synthesis, and gradually becoming a core research topic in the field of educational technology at home and abroad. The analysis and classification of mobile learning research at home and abroad in the past two decades will help deepen the understanding of mobile technology tools and seamlessly apply them to mobile learning practice, so that technology can really promote learning.
\end{abstract}

Index Terms - mobile learning research, review, home and abroad

\section{INTRODUCTION}

The "Wireless Andrew" research project launched in 1994 was the first mobile learning research project in the world. After the project was launched, the global mobile learning research project was launched. Until 2000, Dr. Desmond Keegan, a renowned international distance education expert, introduced mobile learning to China in his report on the 40-year anniversary of Shanghai Television University. In his paper "From Distance Learning to E-Learning to Mobile Learning", Dr. Keegen divides distance learning into three stages: distance learning, e-learning and mobile learning from the perspective of distance education, according to the different forms and means of learning. He is optimistic that these three forms of learning are forming today's distance learning universities, network universities and not yet. Come to Mobile University. In recent years, with the development of mobile technology and application services, as well as the change of learning needs in the information society, education technology, adult education, computer, information technology and other fields began to pay attention to and study mobile learning. Major enterprises (mobile device manufacturers, communication companies) and schools began to explore the practical forms of mobile learning. Nowadays, mobile learning research has gradually become a hot academic topic, which has become the core area of relevant disciplines. After nearly 20 years of research and development, China's mobile learning research has made unprecedented development.

Mobile learning (M-Learning) is a new type of digital learning mode which combines the development of mobile technology and digital learning technology. In Europe and the United States, M-Learning or M-Education is generally referred to, and in China mobile learning or mobile education is generally described.

\section{THE Definition of MobILE LEARNING}

At present, there are different understandings about the definition of mobile learning from different perspectives, which can be roughly divided into three categories: first, mobile learning as a new form of distance education; second, mobile learning as an extension of e-learning; third, from the perspective of cognitive learning, mobile and situational characteristics of mobile learning make it a brand-new one. Technology and learning style.

Mobile learning is a new form of learning that uses wireless mobile communication network technology and wireless mobile communication equipment (such as mobile phone, PDA, Pocket PC, etc.) to obtain educational information, educational resources and educational services. Compared with other forms of learning, mobile learning has the characteristics of convenient learning, individualized teaching, rich interaction and context relevance. (Ye Chenglin et al., 2004)

Some scholars have generalized the definition of mobile learning as a new form of learning that uses wireless mobile communication network technology and wireless mobile communication equipment (such as mobile phones), personal digital assistants (PDA, Pocket PC) to obtain educational information, educational resources and educational services. Mobile learning refers to the learner's ability to obtain information, resources or services at any place and at any time according to their own needs under the support of the network and terminal devices (smart phones, Pads, e-readers, etc.).

\footnotetext{
* Fund projects: Shandong Social Sciences Planning Research Project “Analysis and Mechanism of College Students' English Mobile Learning Adaptation from the Perspective of Dynamic System Theory” (17CWZJ16); Shandong Education Science Planning Project “Application of Mobile Micro learning Based on Mobile Phone Terminal in College English Teaching” (BCGW2017011); Taishan University Teaching Reform Project "Research on the Application Practice and Effect of Mobile Learning Mode of College English Based on Smart-phones" (201617)
} 
It is a new form of distance learning and provides the possibility for learners' lifelong learning (Tang Yueming, 2016).

The Mobile Education Laboratory of Peking University Modern Educational Technology Center defines mobile education as follows: Mobile education refers to the interactive teaching activities that students and teachers use mobile devices (such as mobile phones) more conveniently and flexibly, relying on the mature wireless mobile network, Internet and multimedia technology. Recommunication network technology and wireless mobile communication equipment (such as mobile phones, personal digital assistant PDA, Pocket-PC, etc.) to obtain educational information, en Haifeng (2010) believes that mobile learning is a new form of learning that uses wireless mobile ducational resources and educational services. The goal of mobile learning is to hope that learners can learn anything at anytime, anywhere and in any way.

In Finland, mobile learning is defined as a new way of learning using mobile devices because of the increasing demand for geospatial mobility and flexible learning, which is co-sponsored by Erlcsson, Insite, Telenor Mobile and IT Fornebu Knowation.

Clark Quinn, Director of Knowledge Planet's Cognitive Systems, defines mobile learning from a technical point of view: mobile learning is digital learning through IA devices, including Palms, Windows CE devices and digital cellular phones. When talking about mobile learning, he said, "Mobile learning is the combination of mobile computing and digital learning. It includes learning resources anytime and anywhere, powerful search ability, rich interaction, strong support for effective learning and performance-based evaluation. It is digital learning through information devices such as handheld computers, personal digital assistants or mobile phones. Dye and others define mobile learning as a kind of learning that can be carried out at anytime and anywhere with the help of mobile computing devices. Mobile computing devices used in mobile learning must be able to effectively present learning content and provide two-way communication between teachers and learners. Harris defines mobile learning as the combination of mobile computing technology and digital learning, which can bring learners an experience of learning anywhere and anytime. He further explained that mobile learning should enable learners to enjoy fragmented teaching anytime and anywhere through mobile phones or PDAs, and in this process, wireless information devices are often used more. Chabra and Figueired combine the idea of distance education and make a broader definition of mobile learning: mobile learning is to be able to use any device, at any time and anywhere to receive learning.

To sum up, we can generalize the definition of mobile learning as follows: mobile learning is an extension of digital learning, which means that learners can obtain information, resources and carry out learning anytime and anywhere with the help of miniaturized mobile computing devices and mobile interconnection technology.

\section{A REVIEW OF MOBILE LEARNING RESEARCH}

Mobile learning is a new learning mode with the increasing popularity of multimedia technology and Internet application. It not only emphasizes the learner's subjective status and initiative, but also helps learners construct meanings through various forms of interaction. In view of the important role of mobile learning for learners, the academic community has also discussed mobile learning of English. Domestic research on English mobile learning mainly focuses on the following four categories:

The first is the theoretical model of English mobile learning, which involves the construction and exploration of mobile English teaching or learning mode;

The second is the research on English mobile learning technology, which mainly focuses on the design and development of mobile English learning system;

And the third is the Research on the construction of English mobile learning resources. Including the design and application of mobile learning resource packages, the exploration of integration of information technology or assisted mobile digital learning resource system with English curriculum;

The fourth category is the practical study of English mobile learning, aiming at focusing on the application and Empirical Study of mobile learning in English language competence development, including the empirical study of English listening, speaking and writing teaching and vocabulary teaching. Research on the application of sink learning;

The last one is the survey of the current situation of English mobile learning, aiming at investigating and analyzing the current situation of college students' English mobile learning, putting forward improvement strategies to improve the efficiency of mobile learning, and providing reference for future research.

The classification of English mobile learning research abroad is similar to that in China. It mainly involves the exploration of theoretical models or methods, the technical research of improving English vocabulary level and overall language level, the practical research of improving learners' English listening and writing skills and two or more skills, as well as the exploration of the use of English Mobile Learning strategies.

It can be seen that in recent years, researchers at home and abroad have focused on a single theoretical model, technology and design research, resource construction, strategy use or practical application of mobile learning. Multidimensional comprehensive research on English mobile learning needs to be carried out.

\section{ReSEARCHES On Mobile LEARNING IN CHINA}


Huang Chengyun et al. (2010) constructed a mobile learning system based on cloud computing, which greatly satisfied the learners' demand for timely and accurate access to learning resources. Second, innovations in the application field, such as Pang Chao et al. (2014), proposed a mobile learning system with postal characteristics and high efficiency on the basis of the original distance learning system. Yangye et al. (2014) of Jiangsu Normal University crossed the line. The key points and process of platform resource development and design are elaborated in detail.

\section{B. Research on English Mobile Learning Technology}

In order to improve learners' learning efficiency, the researchers put forward three application modes of mobile learning based on situational awareness, games and enhanced reality (Tang Yueming et al, 2013). Mobile learning has become a new form of distance learning, with high mobility, situational and interactive characteristics, and has realized learners' desire to learn at anytime, anywhere and with them (Zheng Jieqiong, etc.). Scholars Wu Lili et al. (2012) elaborated the key technologies and application prospects of augmented reality technology in smart phone terminal applications; researchers Yang Wenzheng et al. (2007) elaborated the development tool of mobile learning resources, "Flash Lite", and the advantages, processes and key technologies of using "Flash Lite" .

\section{Research on the Theoretical Model of English Mobile Learning}

Huang Ronghuai et al. (2008) introduced the theory, current situation and trend of mobile learning in detail; Fang Haiguang et al. (2011) proposed the roadmap of mobile learning system environment, which includes three levels (mobile learning system equipment environment, mobile learning system support environment, mobile learning system service environment) and six elements (network, terminal, platform, resources, content and activities). Yu Shengquan (2007) systematically combed the three generations of mobile learning from knowledge transfer to cognitive construction, and then to situational cognitive development, which laid a solid theoretical foundation for researchers of mobile learning and had a high academic reference value.

\section{Practical Research on English Mobile Learning}

Chen Yiqin (2013) took adult learners of online NPC as an example, and conducted a questionnaire survey on the current situation and needs of adult distance learners' mobile learning. Reflections mainly focus on rational thinking and practical puzzlement of mobile learning. Liu Bin (2010) proposed that mobile learning should be viewed comprehensively, dialectically and rationally, and mobile learning research should be carried out in combination with specific conditions, so as to maximize its value and avoid "improper" practice.

\section{E. Survey of Mobile Learning in English}

Yuan Yi (2016) combed the relevant literature and research results of mobile learning at home and abroad, based on the theory of lifelong learning and constructivist learning as the theoretical basis of this paper, to explore the current situation of mobile learning in College English. This study is divided into four dimensions: English Mobile Learning Tools, English Mobile Learning Information Resources, English Mobile Learning Behavior and English Mobile Learning Attitude. The application of mobile learning in College English is analyzed by questionnaire and literature. We have a comprehensive understanding of the respondents' gender, grade, specialty, types of autonomous learning and their understanding of mobile learning. Yang Liyuan and Li Jiawei (2015) focused on questionnaire survey, integrated literature analysis, statistical description and other research methods, selected Jiaying College students as the research object, investigated and analyzed the current situation of college students' English mobile learning, and put forward improvement strategies: attaching importance to the promotion of mobile learning, facing the role of mobile learning, setting learning goals scientifically, enhancing self-monitoring awareness, and benefit. Build a mobile learning platform with social tools. Yang Lin et al. (2014) surveyed and analyzed the current situation of mobile learning by using smartphones among college students in Gansu Province through statistical questionnaires, explored the needs and expectations of students for mobile learning, and put forward conclusions and suggestions for future research on mobile learning. Lin Moujin and Huang Huibin (2014) analyzed the current situation of College Students' understanding of mobile learning, the conditions of mobile learning, the utilization of mobile learning resources, the selection of mobile learning content and the effect of mobile learning through a questionnaire survey of mobile learning among college students in Xiamen. In view of the existing problems, the paper put forward some suggestions and strategies to improve the efficiency of mobile learning among college students. Miao Hongyan et al. (2014) established a model of College Students' mobile learning behavior based on TAM model. Taking the students of a comprehensive university in Jiang su as the research sample, using the method of questionnaire survey and using SPSS to test the hypothesis of the model, it was found that college students' mobile learning behavior was influenced by perceived usefulness of mobile learning and their attitudes towards mobile learning. The perceived usability of mobile learning is determined by perceived usefulness and ease of use; the perceived ease of use of mobile learning is determined by perceived convenience of mobile learning and the degree of personalized choice; the perceived usefulness of mobile learning is determined by the needs of interpersonal relationships and perceived ease of use of mobile learning; the survival needs of College students and the needs of individual growth and development have no usefulness to perceived mobile learning. Significant impact. Zhang Yumei and Wang Xueming (2012) analyzed the current situation of mobile learning of Yinchuan University students through questionnaires in order to understand the mobile learning equipment, attitudes and 
behaviors that college students often adopt in order to provide reference for the development of mobile learning system and learning resources. Zhang Jieyin and Zheng Yanlin (2011) selected some college students as the research object to conduct a questionnaire survey, based on data analysis of College Students' attitudes and needs for mobile learning. Zhang Hao et al. (2010) Through the analysis of some students' understanding and interest in mobile learning in Yangzhou University, pointed out the difficulties encountered by college students in the process of mobile learning, and put forward their own opinions and suggestions on the development and design of mobile learning. Wu Shuting (2009) analyzed the current situation of College Students' mobile learning from three dimensions: learning tools, learning resources and learning behavior, using questionnaire, literature and interviews.

\section{Researches on Mobile Learning Abroad}

Researches abroad on mobile learning mainly focuses on some developed countries in Europe and North America. Stanford University's "Mobile Phone Learning" project is a precedent to explore the field of mobile learning. It is also a classical experimental study, which has a high international reputation.

\section{A. Discussion on Theoretical Model or Method}

Forhberg et al. (2009) strictly screened 102 mobile learning projects before 2007. Using the task model of Mobile Learners proposed by Sharples and Taylor, each project was analyzed based on six dimensions: context, tools, control, communication, subject and object (goal), and typical items in each dimension were introduced. The study creatively proposes that mobile learning can better support learning in the corresponding context, but it requires learners to use knowledge in the context rather than get knowledge. Because novice learners are often difficult to use knowledge, the participants of mobile learning should first locate themselves in advanced learners, so as to bring into play the maximum potential of mobile learning as a tool to stimulate deep reflection, communication and cooperation. This view is the third cognitive orientation of mobile learning mentioned by the author.

\section{B. Exploring the Use of English Mobile Learning Strategies}

Keskin and Metcalf (2011) combed the research literature of mobile learning in various fields including enterprises, universities and the army from the perspective of mobile learning theory. They listed behaviorism, cognitivism, constructivism, connectionism, situational learning, problem-based learning, location-based learning, context-aware learning, collaborative learning, and so on. Conversational learning, lifelong learning, informal learning, sociocultural theory, activity theory, navigation theory and so on. Combining with practical projects, this paper sorted out the implementation points of mobile learning which each learning theory concerned and the mobile technology which it mainly relied on. Ting studied a new form of cooperative learning in 2013: interwoven learning. This kind of learning is not only a conventional way to promote students' collective problem solving by mobile technology, but also an integration of learner-learner, learner-content, learner-instructor interaction in mobile technology, from communication itself to knowledge.

\section{Technical Research on Improving English Vocabulary Level and Language Overall Level}

Motiwalla (2007) affirmed the development prospects of mobile learning and pointed out that some technical problems, such as the use of human-computer interface, may become the bottleneck of the development of mobile learning. Tabuenca and Kalz (2015) and other researchers take New Zealand college students as subjects. When learning geography knowledge, how mobile technology helps learners self-regulate the learning time of each chapter. Through monitoring training, students' ability of time monitoring has been significantly improved, and their academic performance has been steadily improved. Antonio Garcia-Cabot (2013), a scholar from the University of Alcala in Spain, conducted an empirical study on the use of adaptive mobile systems in mobile learning to assess learning content and skills, skills and situations. The results show that compared with e-learning, mobile adaptation has a limited impact on the performance of practical skills learning. Researchers also collected information about the context of mobile system usage and compared it with traditional computer access. The results show that students learn in similar environments independently of the way they use to acquire learning content.

\section{A Practical Study of English Listening and Writing Skills and More than Two Skills of High-level Learners}

Olga Viberg (2013) took 345 college students from Sweden and China as subjects to investigate their attitudes towards mobile devices in second language and foreign language learning under different cultural backgrounds. The survey results show that the respondents' attitudes towards mobile learning are very positive. The top three factors leading to their positive attitudes are: personalization of mobile learning (83\%), collaborative spirit required for mobile learning (74\%) and authenticity of resources obtained through mobile devices (73\%).

\section{CONCLUSION}

In 2012, the Ministry of Education issued the Ten-Year Development Plan of Educational Informatization (2011-2020). It pointed out that higher education informatization is an effective way to promote higher education reform, innovation and quality improvement, as well as an innovative frontier of educational informatization 
development. It also put forward that by promoting the deep integration of information technology and education and teaching, promoting the modernization of educational content, teaching means and methods, and realizing personnel training. Innovation of Nurturing Model (No. 5 of Education Technology [2012]. Mobile learning, with its advantages of mobility, wireless, portability and resource sharing, will not only fill the gap of traditional learning, but also become a new hot spot of educational informatization (Huang Zhenyi, 2017).

As a new way of learning with the increasing popularity of multimedia technology and Internet applications, mobile learning makes learning more free and unconstrained, and greatly improves learning efficiency. At the same time, mobile learning emphasizes learners' subjective status and initiative, which is more dependent on the development of information technology and mobile device applications. Through digital simulation, collaborative learning and conversational interaction modules are created. Mobile learning can effectively help learners visualize their learning management, give full play to their "situation", "collaboration", "conversation" and "management" functions, and help learners construct meanings (Yang Yang, 2016). However, in recent years, most of the research on mobile learning focuses on the practical research of technology and design. The Strategy Research Based on theory is not systematic and in-depth. Some researchers (Chen Weichao, Liu Navy, 2009; Liu Yandong, 2012; Mou Hongwei, 2017, etc.) try to study the instructional design of mobile learning under the guidance of constructivist learning theory, but there is no structure. We should make up for the shortcomings of the above research in future research. Under the background of current teaching informationization, we should adopt scientific learning theory to guide the construction of contemporary college students' English mobile learning model, carry out teaching practice, and adopt quantitative and qualitative research methods to verify the learning effect, and propose changes. Make suggestions to maximize the learning effect.

\section{REFERENCES}

[1] Chen Yiqin. (2013). Investigation and Research on mobile learning status of adult learners. China Distance Education, 10,47-52+96.

[2] Fang Haiguang, Li Zhenzhen, Wang Xiaochun, Liu Min. (2011). Systematic Service Environment of Mobile Learning. Modern Education Technology, 04,19-25.

[3] Fang Haiguang, Mao Ying, Liu Jun, Wang Hongyun. (2011). Systematic Support Environment for Mobile Learning. Modern Education Technology, 03,15-20.

[4] Fang Haiguang, Liu Min, An Sufang. (2011). Research on System and Equipment Environment of Mobile Learning . Modern Education Technology, 02, 22-27.

[5] Fang Haiguang, Wang Hongyun, Huang Ronghuai. (2011). Road Map of System Environment for Mobile Learning: A Review of Case Studies on Mobile Learning Research and Application at Home and Abroad . Modern Education Technology, 01, 14-20.

[6] Fu Jian, Yang Xue. (2009). A ten-year overview of the theoretical research and practice of mobile learning in China . Audiovisual Education in China,07, 36-41.

[7] Huang Chengyun, Zuo Mingzhang, Rong Xianhai. (2010). Design of Mobile Learning System Based on Cloud Computing . Modern Education Technology,08, 102-105.

[8] Huang Ronghuai. (2008). Reflections on Educational Informationization --- Also on the Construction of Educational Informationization in the Transitional Period . China Educational Informationization,21, 14-16.

[9] Liu Bin. (2010).Re-examination of some problems of mobile learning. Journal of Distance Education,05,92-96.

[10] Lin Moujin, Huang Huibin. (2014). Investigation and Research on the Current Situation of Mobile Learning of College Students - Taking a University in Xiamen as an example . Journal of Jimei University (Educational Science Edition),02,20-24.

[11] Miao Hongyan, Liu Xiangchen, Wu Xianghui. (2014). TAM Model Perspective of Mobile Learning Behavior of College Students: A Case Study of a University in Jiangsu Province . Academic Exploration, 02,76-79.

[12] Pang Chao, Liu Qian, Liu Qingfang. (2014). Research on Post Mobile Learning System Based on Android. Science and Technology Bulletin, 04,232-235.

[13] Ren Haifeng, Zhao Jun. (2010). An analysis of the research status of mobile learning at home and abroad. Adult Education,01, 95-96.

[14] Tang Yueming, Fu Xiaoli and Bucaili. (2016). A review of mobile learning research in recent ten years. China Distance Education, 07, 36-43+80.

[15] Wang Youmei, Wang Juan, Yang Xiaolan and Wu Haiyan. (2013). Current status and future trends of mobile learning in China in recent 20 years: a review based on the comparison between China and the West. Modern distance education research,01, 49-55.

[16] Wu Lili, Li Ziyun, Zhang Tian. (2012). Application of Augmented Reality Technology in Mobile Learning. Modern Education Technology, 07, 98-100.

[17] Wu Shuting. (2009). Research on the Current Situation of Mobile Learning of College Students. Master Dissertation. Nanchang University.

[18] Yang Lin, Zhu Zhengping and Feng Jie. (2014). Investigation and analysis of mobile learning status of college students based on smartphones. Automation and Instruments, 05, 202-205.

[19] Yang Liyuan, Li Jiawei. (2015). Survey and analysis of the current situation of college students' English mobile learning. Software Guide (Educational Technology),07,51-53.

[20] Yang Wenzheng, Zou Xia. (2007). Flash Lite: New Technology for Mobile Learning Resource Development. Modern Education Technology, 11, 64-66.

[21] Yang Ye. (2014). Design and Development of Classroom Integration Mobile Learning Resources. Master Dissertation. Jiangsu Normal University. 
[22] Yu Shengquan. (2007). From Knowledge Transfer to Cognitive Construction, to Situational Cognition: Development and Prospect of Three Generations of Mobile Learning. China Audiovisual Education,06, 7-18.

[23] Zhang Hao, Yang Lingxia, Chen Pan. (2010). Investigation and analysis of mobile learning status of college students. Software Guide (Educational Technology),01, 48-50.

[24] Zheng Jieqiong, Chen Zeyu, Wang Minjuan, and Jason Wu. (2012). The exploration and practice of mobile learning under the $3 \mathrm{G}$ network . Open Education Research,01,159-162.

[25] Zhang Qiyin, Zheng Yanlin. (2011). Survey and analysis of mobile learning needs of college students. Software Guide (Educational Technology), 05 ,26-28.

[26] Zhang Yumei, Wang Xueming. (2012). Investigation and Research on the Current Situation of Mobile Learning of College Students . Computer Education,05, 17-20.

Jiaosheng Qiu was born in Tengzhou, China in 1983. He received his master's degree in foreign linguistics and applied linguistics from Shandong Agricultural University, China in 2012.

$\mathrm{He}$ is currently a lecturer in the Department of College Foreign Languages Teaching, Taishan University, Tai'an, China. His research interests include Second Language Acquisition and College English Teaching. 